\title{
Bibliotecas Públicas e escolares nos discursos de Cecília Meireles e Armanda Álvaro Alberto: acervos e práticas de leituras
}

\section{Marcus Vinicius Rodrigues Martins}

Bibliotecário e Mestre em Ciência da Informação pela Universidade Federal de Minas Gerais.

http://dx.doi.org/10.1590/1981-5344/2282

Apresenta um panorama dos discursos educacionais de Cecília Meireles e Armanda Álvaro Alberto que, nas décadas de 1930 e 1940, lutaram por uma educação pública, leiga e de qualidade. $O$ artigo relata 0 engajamento de ambas com questões ligadas às Bibliotecas Públicas e Escolares e recupera as ideias de Cecília Meireles e Armanda Álvaro Alberto sobre temas como: a escolha de livros para crianças; a construção de uma literatura infantil com características e peculiaridades próprias; projetos educativos; formação do acervo e os estudos sobre as leituras de crianças e jovens. Além disso, são descritas algumas experiências daquela que é considerada a primeira biblioteca pública infantil no Brasil, o "Pavilhão Mourisco", iniciativa de Cecília Meireles, assim como os projetos de leitura voltados para crianças, adolescentes e adultos de Armanda Alvaro Alberto. Ademais, discute-se a importância das bibliotecas para o desenvolvimento sócio-educativo de crianças, jovens e adultos e a presença decisiva do bibliotecário como mediador da tríade livro-leitura-biblioteca.

Palavras-chave: Bibliotecas Públicas. Bibliotecas Escolares. Livros. Leitura. História das bibliotecas. História da Educação.

\section{Public and school libraries in the speeches of Cecília Meireles and Armanda Alvaro Alberto: collections and readings practices}


It Presents an overview of the educational discourses of Cecília Meireles and Armanda Álvaro Alberto who, in the 1930s and 1940s, fought for a public, lay and quality education. The article reports the engagement of both women with issues related to Public and School Libraries and retrieves the ideas of Cecilia Meireles and Armanda Álvaro Alberto on topics such as: choosing books for children; the construction of a children's literature with its own characteristics and peculiarities; educational projects; Creation of collection and studies on the readings practices of children and juveniles. Furthermore, some experiences of what is considered the first children's public library in Brazil, "Pavilhão Mourisco", an initiative of Cecília Meireles, as well as reading projects aimed at children, teenagers and adults created by Armanda Álvaro Alberto. Moreover, it is discussed the importance of libraries to the socio - educational development of children, juveniles and adults and the decisive presence of the librarian as the mediator of the Triad book-readinglibrary.

Keywords: Public Libraries. School Libraries. Books. Reading. History of libraries. History of Education.

Recebido em 23.11.2014Aceito em 09.12.2014

\section{Introdução}

O presente artigo apresenta os discursos de Cecília Meireles e Armanda Álvaro Alberto que nas décadas de 30 e 40 apareceram na cena educacional e destaca o papel das duas educadoras que lutaram a favor da educação gratuita, leiga e de boa qualidade para todas as crianças, jovens e adultos. Ambas foram signatárias do manifesto dos "Pioneiros da Educação Nova" de 1932, e assim como Lourenço Filho, Fernando de Azevedo e Anísio Teixeira, buscaram aplicar as ideias da escola nova nos métodos, práticas e espaços escolares. No caso de Cecília Meireles e Armanda Álvaro Alberto, as reformulações convergiam para as Bibliotecas Públicas ou Escolares, e consequentemente os livros e as práticas de leitura.

O objetivo desta discussão é mostrar como as duas educadoras expressavam ideias e posicionamentos em relação às bibliotecas e também em relação aos acervos, a construção do gosto e hábito pela leitura e aos espaços destinados a crianças, jovens e adultos em processo de aprendizagem.

As fontes utilizadas para organização deste texto foram teses, dissertações, livros e artigos que tratavam da trajetória de Cecília Meireles e de Armanda Álvaro Alberto; somam-se a estes os escritos produzidos 
pelas duas educadoras, como os textos publicados por Cecília Meireles entre 1930 e 1933 na coluna "Comentário" da "Página de educação", seção dirigida por ela no Jornal Diário de Noticias da Cidade do Rio de Janeiro que esta reunida na Coletânea "Crônicas de Educação".

Dentre os escritos de Armanda Álvaro Alberto foram analisados os publicados em artigos do "Jornal do Commercio", e proferidos nas palestras das Conferências Regionais de Educação, todos entre 1928 e 1932. Os textos estão reunidos no livro "Armanda Álvaro Alberto" da coleção Educadores editada pelo Ministério da Educação.

Ao analisar os discursos proferidos por estas educadoras, o artigo propõe resgatar o pensamento social, educacional e cultural vigente na década de 1920, de forma que o trabalho abre perspectiva para a investigação de estratégias argumentativas que compõem os discursos pedagógicos de outros sujeitos que estavam na cena educacional brasileira e busca contribuir para apreensão da instituição bibliotecária.

\section{Livros, leitura e bibliotecas}

O final do século XIX e início do século XX foram marcados por uma profusão de discursos educacionais, que viam a escola como espaço privilegiado para instruir e educar os futuros cidadãos e membros da sociedade. A escolarização obrigatória e generalizada passa a representar um aspecto decisivo tanto para o progresso individual, quanto para 0 social, ou seja, "o crescimento do número de alunos, da demanda por instituições de ensino e de estudos científicos sobre a infância levou à criação de uma nova escola" (GREIVE, 2007, p. 217).

A escola tradicional não bastava para educar os novos membros da cidade, era necessário reformar a instituição. Desta forma, a "escola nova" proposta por educadores e intelectuais apresentava uma concepção dinâmica de aprendizagem: excursões, jogos, exercícios físicos eram apontados como atividades indispensáveis; o alunado deveria estar em constante movimento. "Reforçar esta imagem cinética da educação significava demarcar fronteiras com o ensino tradicional denominado pelos escolanovistas" (VIDAL, 1998, p. 89).

Toda esta prática voltada para as atividades do movimento parecia colocar a leitura e os livros alijados dos processos ativos de aprendizagem, pois de que forma os alunos sentados em posições estáticas nas cadeiras, com práticas silenciosas poderiam estar envoltos nas concepções ativas? Neste sentido Vidal (1993) disserta que a ideia de uma educação cinética, não se restringia à ação física, mas determinava uma nova atitude frente à aquisição de conhecimento, ou seja, mesmo sentados, em silêncio, alunos e alunas poderiam estar "ativamente" envolvidos com a aprendizagem.

Deste modo, educadores, escritores e intelectuais identificados com - pensamento escolanovista dedicaram-se a construir "novas práticas discursivas em torno do livro e da leitura, modelando seu uso escolar e normatizando as formas de apropriação do lido" (VIDAL, 1998, p. 91). De 
forma que também, o espaço dedicado à prática do ler, isto é a biblioteca também sofria remodelações em seu ambiente, práticas, acervos e organização.

Destacaram-se dentro deste movimento, duas educadoras cariocas que defenderam a causa da educação. Cecília Meireles e Armanda Álvaro Alberto que foram signatárias do Manifesto dos Pioneiros da Educação Nova, histórico documento redigido por Fernando de Azevedo e assinado por 26 intelectuais, publicado em 1932. Ambas estiveram à frente das campanhas contra o analfabetismo e da Associação Brasileira de Educação (ABE) e acreditavam na educação como forma de elevação individual e social e para isso, construíram maneiras para que o ideário pedagógico escolanovista se efetivasse.

A trajetória de Cecília Meireles e Armanda Álvaro Alberto convergiam no mesmo sentido, pois as duas observavam a importância dos livros, leituras e das bibliotecas para a escolarização e discursavam a favor de reformulação dos conteúdos dos livros infantis e juvenis para adequação às crianças e adolescentes, e também pela difusão de bibliotecas infantis e populares.

\section{Os discursos de Cecília Meirelles}

Cecília Benevides de Carvalho Meireles, natural da Cidade do Rio de Janeiro, nasceu em 7 de novembro de 1901. Cursou a Escola Normal do Instituto de Educação do Rio de Janeiro. Conhecida autora de vários gêneros literários - poesia, prosa, conto e crônica - Cecília Meireles desenvolveu intensa e marcante atividade como educadora, e utilizou os jornais para professar suas perspectivas no campo da Educação, assinando por vários anos, entre outras, a coluna "Páginas de Educação", no Diário de Noticias do Rio de Janeiro.

Engajada com as questões educacionais e literárias, a autora e poetisa discursava sobre os temas, livros, leituras e biblioteca sob a perspectiva do ideário escolanovista e buscava construir um dialogo entre as áreas. Neste sentido, para a autora a leitura não correspondia a um passatempo, e sim uma "nutrição" (MEIRELES, 2001, p. 28). Portanto, era necessário ofertar bons livros que ocupassem o tempo disponível pela leitura, e consequentemente proporcionasse bons momentos de aprendizagem.

Avivar o interesse pela leitura para construir o gosto pela leitura era um dos argumentos para constituir um bom livro para a criança de forma que para Cecília Meireles (2001), o empenho de compreender a criança ou para adivinhar sua predileção tornava-se um esforço para a escrita, "é um abalo para sensibilidade dos que realmente se interessam pela infância pensar nas sugestões que se podem encerrar num livro que vai parar nas mãos da criança, e que seus olhos avidamente se põem a percorrer". (MEIRELES, 2001, p. 128)

Defensora da literatura infantil, a autora advogava que era preciso colocar à disposição da criança diversos livros, mas dotados de valor 
cientifico, poético e moral. De forma que o livro deveria ser útil, posto de maneira agradável para um melhor aproveitamento pelo leitor de suas mensagens. Para a poetisa e educadora era necessário, contudo, que se ofertassem bons livros, porque entre "não ler" e "ler" um livro ruim, era preferível "não ler".

Meireles (2001) acreditava na importância do livro para a formação do individuo e entendia que poderia ser "o melhor", ou também o "pior" dos elementos de auxilio da educação das crianças. Desta maneira, afirmava ser preciso que os responsáveis pelos infantes lessem os livros antes de confiarem a elas.

Um livro de literatura infantil é, antes de mais nada, um obra literária. Nem se deveria consentir que as crianças frequentassem obras insignificantes, para não perderem tempo e prejudicarem seu gosto. Se considerarmos que muitas crianças, ainda hoje, têm na infância o melhor tempo disponível da sua vida; que talvez nunca mais possam ter a liberdade de uma leitura desinteressada, compreenderemos a importância de bem aproveitar essa oportunidade. Se a criança, desde cedo, fosse posta em contato com obrasprimas, é possível que sua formação se processasse de modo mais perfeito. (MEIRELES, 1979, p. 96).

Cecília Meireles toca em um ponto importante, a liberdade de escolha dos livros, mas acima de tudo, uma vigilância na qualidade. Os livros como é dito pela educadora podem ser prejudiciais na educação das crianças. Neste ponto, fica nítido um campo discursivo que demonstra lutas pelo poder de designar boas leituras; de modo que "existia um movimento de censura. O lugar da autoridade no campo educacional, ou quem o educava, de que era preciso escolher, ou melhor, muitas vezes, abster-se das leituras, para que elas não o contaminassem." (KLINKE, 2003, p. 185)

O considerado 'bom' livro para criança, tanto em seu conteúdo, quanto na sua qualidade e organização deveria conter elementos que atraíssem o leitor e o instigassem à leitura, pois Cecília Meireles mencionava que nem sempre o mais belo livro era o que apresentava um conteúdo rico e harmônico e enfatizava,

Os livros que mais têm durado não dispunham de tamanhos recursos de atração. Neles, era a história, realmente, que seduzia - publicidades, sem cartonagens vistosas, sem os mil recursos tipográficos que hoje solicitam adultos e crianças fascinando-os antes de se declararem, como um amor à primeira vista (MEIRELES, 1979, p. 33).

A escritora ao mencionar sobre os conteúdos dos livros, também denunciava as ações tipográficas e as propagandas que tentavam persuadir e impor determinados livros. Para Meireles cabia, também aos 
escritores a responsabilidade sobre seus escritos, e neste sentido, advogava que escrever livros infantis era uma ciência e uma arte, pois era necessário conhecer as condições, o funcionamento e as características da infância. Este conhecimento permitiria perceber todo o infinito que as palavras comportam, "os escritores deviam produzir obras com linguagem acessível ao público infantil, respeitando as possíveis dificuldades de sua compreensão aos vocabulários difíceis" (MELLO; MACHADO, 2008, p. 14).

Neste sentido, quando o autor conseguisse elaborar todos os pontos descritos acima, o mesmo atingiria a "arte", pois para Meireles "se não estivermos diante de alguém que tenha o dom de fazer de uma pequena e delicada coisa uma completa obra de arte, não possuiremos o livro adequado ao leitor a que se destina" (MEIRELES, 2001, p. 121).

A falta da relação entre ciência-arte, na perspectiva de Cecília Meireles, era a falta de dedicação e adequação ao universo infantil. Os autores de livros infantis escreviam narrativas "fantásticas", rebuscadas, que não condiziam com o vocabulário da infância. Outros escreviam narrativas muito simples, e enxergavam a criança como um público pouco exigente.

Para tentar amenizar o excesso de estímulo exterior ás crianças, as bibliotecas possibilitariam a escolha de livros adequados para a infância que objetivassem o desenvolvimento educacional e social das crianças.

Neste sentido, a biblioteca compreendia o espaço que colaboraria para a construção e o gosto pela leitura, e consequentemente o hábito de ler. Desta forma, deveria ser agradável, prazeroso e adequado às necessidades e interesse infantil. Portanto, a forma do mobiliário, as estantes e o ambiente deveriam se ajustar a criança; desta forma, estantes baixas permitiriam que a criança escolhesse o livro que a agradasse e possibilitaria construir uma relação de prazer com o título, a capa e a plasticidade da edição.

Para a poetisa, as bibliotecas colaborariam para que o adulto percebesse as preferências das crianças, "pois pela escolha feita, entre tantos livros postos em sua disposição, a criança revela o seu gosto, as suas tendências e os seus interesses (MEIRELES, 1979, p. 111).

No tocante as bibliotecas, Cecília Meireles, após a revolução de 1930, durante a gestão de Anísio Teixeira como Diretor da Instrução Pública no Distrito Federal, "foi designada para o Instituto de Pesquisas Educacionais. Poucos dias depois organizava, com a colaboração do escritor Alfonso Reyes, então embaixador do México no Brasil, e de duas estagiárias, uma Biblioteca Popular Infantil". (SOARES, 2005, p. 446).

O Pavilhão Mourisco como era chamado, de início era para ser uma biblioteca infantil pública, porém, na inauguração de 15 de agosto de 1934 foi denominada de Centro Cultural Infantil. Para Lobo (2010, p. 53) "a biblioteca infantil representa um dos sonhos vividos da educadora, em uma fase de sua vida de grandes realizações, pois significava tornar realidade todas às possibilidades para criar o mundo para crianças". O Pavilhão Mourisco representou a concretização dos sonhos de Cecília 
Meireles, e acima de tudo a corporificação do ideário escolanovista em relação às bibliotecas, livros e leitura.

O Pavilhão Mourisco foi à primeira biblioteca infantil do Brasil e foi considerado um dos principais projetos da gestão do Anísio Teixeira. O espaço era tido por este como "Casa da Criança". De fato, o nome condizia, pois o lugar ambientava um mundo encantado. Além disso, "Na época havia bibliotecas que jamais permitiam a entrada de crianças, outras que somente consentiam o acesso de menores acompanhados dos pais. A biblioteca do Mourisco foi além". (PIMENTA, 2001, p. 117).

O lugar não somente estimulava a frequência, como a funcionalidade da decoração das salas, ambientadas em cada seção, trazia uma inovação surpreendente e espetacular: o mobiliário. Para Lobo (2010) a sala de leitura era organizada com estantes de livros e mesas ao alcance da criança, coloridas, com potes de barros com flores que encantavam crianças e adultos.

A biblioteca possuía um acervo de literatura infanto-juvenil, selecionado a partir do inquérito que a educadora efetuou entre novembro e dezembro de 1931, recolhendo questionários e tabulando respostas de estudantes cariocas do terceiro ao quinto ano da escola primária, e que ela publicou em 1934. O questionário consistia na identificação de preferencias e aversões quantos aos livros, autores, gêneros e práticas de leitura de adolescentes e crianças. Na perspectiva de Cecília Meireles, as "bibliotecas infantis correspondiam a uma necessidade da época, pois têm a vantagem não só de permitirem à criança uma enorme variedade de leituras, mas de instruírem os adultos acerca de suas preferências". (MEIRELES, 2001, p. 111).

As escolhas dos alunos feitas em tantos outros livros postos a sua disposição revelaria o seu gosto, as suas tendências e os seus interesses (MEIRELES, 2001). No mais, a biblioteca infantil incluía nove seções que são descritas por Jussara Pimenta (2001, p. 112-113).

A biblioteca era constituída de nove seções. A primeira era a da biblioteca propriamente dita, que possuía inicialmente 720 obras. [...] A segunda seção era a de gravuras, com 2.781 unidades, compreendendo toda a documentação gráfica relativa ao Brasil: história, arte, ciência, trabalho etc. A terceira era de cartografia, compreendendo globos, mapas do Brasil e dos Estados, do mundo, da América e da cidade do Rio de Janeiro, plantas topográficas, bandeiras, etc. A quarta seção era a de recortes, com 32 álbuns sobre vários assuntos, similares a uma enciclopédia, seção também responsável pela edição de A Gazetinha, jornal mural de informação diária. A quinta seção era constituída de selos e moedas, compreendendo coleções, devidamente estudadas e catalogadas, de moedas e selos do Brasil. A sexta, de música e cinema, possuía um aparelho Pathe Baby, rádio, radiola e discos. A sétima previa atividades artísticas como hora do conto, arte dramática etc. A oitava seção, de propaganda e 
publicidade, era responsável por estabelecer a comunicação da Biblioteca Infantil com as escolas e o público em geral, publicar o Boletim mensal com o resumo das atividades do mês anterior e das projetadas para o mês seguinte, apresentar relatório trimestral informando o Departamento de Educação das medidas e verificações técnico-administrativas de cada seção, expedir comunicados, realizar intercambio infantil e publicar material julgado útil à finalidade do estabelecimento e de acordo com sua natureza. Finalmente, a nona seção, de observações e pesquisas, tinha como objetivo realizar trabalhos de investigação pedagógica determinadas pelo Departamento de Educação ou para uso especial da Biblioteca Infantil e relacionados com as atividades que the eram inerentes, através de levantamento diário da preferência de leitura do público infantil.

Entretanto, em 1935 tornou-se difícil continuar os trabalhos no Pavilhão Mourisco. Em 1937, após três anos de funcionamento, a biblioteca é invadida pela Polícia do Estado Novo sob a acusação de divulgar literatura comunista - As aventuras de Tom Sawyer, de Mark Twain, era a prova da improbidade. Os jornais do Rio de Janeiro publicaram a notícia de desativação da biblioteca, por "infundados motivos políticos". (LOBO, 2010, p. 57).

A experiência do Pavilhão Mourisco, apesar da breve duração, representou a semente que mais tarde frutificaria na criação das seções infantis das bibliotecas públicas e de bibliotecas infantis no Rio de Janeiro, São Paulo, Belo Horizonte e outros municípios. Para Pimenta (2001) o pioneirismo desse empreendimento reside no fato de essa biblioteca possuir características antes nunca vista no Brasil.

\section{Os discursos de Armanda Álvaro Alberto}

Armanda Álvaro Alberto nasceu em 10 de Junho de 1892 no Rio de Janeiro, filha do Dr. Álvaro Alberto Silva e de Maria Teixeira da Motta e Silva; a educadora teve formação doméstica com sua mãe e com alguns professores particulares. Só ingressou na escola aos 14 anos de idade para fazer um curso de literatura inglesa, ministrado no Colégio Jacobina, sendo que, posteriormente em 1917, iniciaria sua carreira como professora. Mesmo com sua entrada tardia na escola, Armanda sempre viveu em um ambiente de discussões políticas e preocupações científicas. 
Em 1919 por causa do seu irmão: Álvaro Alberto Motta e Silva ${ }^{1}$ que servia na Marinha, Armanda passou uma temporada em Angra dos Reis, onde fundou uma escola ao ar livre para pescadores. A partir da experiência, criou em 13 de fevereiro de 1921 a Escola Proletária de Meriti, localizada na cidade de Duque de Caxias (RJ). Entretanto, o nome foi mudado para Escola Regional de Meriti, "o projeto da Escola Proletária angariou o apoio da Liga Brasileira contra o Analfabetismo e da firma F. Venâncio \& Cia, fabricante dos explosivos Rupturita em Meriti e de propriedade de seu irmão Álvaro Alberto" (MORAES, 2006, p. 2)

O objetivo da instituição era atender alunos de classes populares, pois a "educadora acreditava que o desafio de levar educação a todos era dever de toda a sociedade e não apenas dos poderes públicos" (MIGNOT, 2010 , p. 24). Esta convicção a levou a assinar vários manifestos como "Manifesto dos Pioneiros da Educação Nova" em 1932 e a participar de numerosas campanhas e lutas em defesa da Educação.

Armanda Álvaro Alberto teve participação decisiva no Manifesto da Escola Nova, juntamente com seu marido Edgar Süssekind de Mendonça, também signatário do manifesto, e tentaram recriar na Escola Regional de Meriti os ideais propostos pelo movimento escolanovista.

Quanto à organização geral, a preocupação de ser lugar de experimentação científica; estava situada no campo, em regime de co-educação; ministrava trabalhos manuais com fins educativos, mais que profissionais; estimulava a jardinagem, criação de animais, tempo livre para trabalhos extraclasse, como ginástica e excursões. No âmbito da formação intelectual, privilegiava o espírito crítico, em lugar da memorização. Fatos e experiências tinham precedência sobre o ensino livresco. Baseava-se na atividade, na expressão espontânea da criança por meio dos desenhos, jogos e trabalhos coletivos. A disciplina, parte da formação moral, não era imposta, e os alunos participavam do funcionamento escolar. Não estimulava a competição, nem aplicava castigos. O ambiente procurava ser bonito, ordenado, higiênico (MIGNOT, 2010, p. 28).

Neste sentido, a educadora buscou colocar o aluno no centro do processo educativo, como era sugerido pelo ideário da escola ativa. Uma das ações para a efetivação das propostas escolanovistas, era integração comunidade e escola. Neste sentido, a educadora criou o círculo de mães, que tinha como finalidade realizar a integração da família com a instituição escolar; estas eram responsáveis pela merenda escolar ${ }^{2}$. E

\footnotetext{
Álvaro Alberto Motta e Silva foi cientista consagrado, que atualmente, dá nome a mais importante condecoração nacional na área de ciência e tecnologia, conferida pelo presidente da República. Após receber as primeiras lições sob orientação da mãe e de professores particulares, ele estudou na Escola Politécnica e na Escola Naval. A partir de 1925, aperfeiçoou seus estudos em Bruxelas. Ingressou na Marinha onde chegou ao posto de almirante. Foi um dos fundadores da Academia Brasileira de Ciência e do Conselho Nacional de Desenvolvimento Científico e Tecnológico (CNPq) e notabilizou-se pelos estudos pioneiros na área de energia nuclear, influenciando a política nacional neste setor. (MIGNOT, 2010).

${ }^{2}$ A escola regional de Meriti, também era chamada pelos alunos, mães e comunidade como "mate com angu", pois oferecia aos alunos, alimentos a base de milho e chá mate como merenda escolar.
} 
criou uma biblioteca aberta ao público, iniciativa pioneira na região, que tinha como objetivo a escolarização extraescolar de alunos, jovens e adultos.

A educadora sempre dedicou atenção especial às bibliotecas por sua importância social e cultural e também por sua colaboração no processo de escolarização de crianças, adolescentes e adultos Para Armanda "uma só condição é exigida a quem toma a si a tarefa de ensinar: gostar, gostar muito de crianças e de livros". (ALBERTO, 1932, s/p.).

A educadora pensava que havia "grande necessidade da instalação de bibliotecas nos estabelecimentos de ensino". (ALBERTO, 1928, s/p.) 0 acervo amplo e diferenciado das mesmas cooperaria para modificar e sanar o panorama de leitura do alunado. Para compreender as preferências infantis e juvenis em relação aos livros que comporiam os acervos; Armanda Álvaro Alberto em 1926 realizou um estudo sobre as leituras e predileções de livros por crianças e adolescentes entre 08 e 17 anos e alunos de escolas públicas e participantes. A pesquisa concluiu que o gênero não influenciava na escolha dos livros; os autores brasileiros e portugueses conseguiam agradar muito pouco os adolescentes, porém as "péssimas traduções de romancistas franceses, alguns bem medíocres são estimadíssimas". (ALBERTO, 1928, s/p.).

O estudo também identificou que os adolescentes desconheciam obras primas universais; de acordo com a educadora "é como se os grandes poetas e prosadores houvessem sempre escrito fora do seu alcance" (ALBERTO, 1928, s/p.). A educadora via a necessidade de organizar edições de grandes autores, principalmente os nacionais, que adaptassem à leitura dos adolescentes.

A pesquisa constatou a falta de bibliotecas e de um acervo literário na escola, de acordo com a educadora "só de uma escola municipal foram inutilizados 100 votos por se referirem a obras didáticas adotadas em sua classe". (ALBERTO, 1928, s/p.) Desta forma, Armanda pensava que as presenças de bibliotecas poderiam modificar este quadro.

Neste sentido, quando esteve na Associação Brasileira de Educação, entidade composta de intelectuais da área de educação que debatiam temas educacionais, a educadora esteve a frente das atividades ligadas a proposições de políticas editoriais e bibliotecas voltadas para crianças e adolescentes. Em uma resenha publicada pelo Jornal "O Estado" em 1932, mencionava que a criação das instituições visava "instruir as crianças no uso dos livros e das bibliotecas como instrumentos de trabalho, treinar as crianças em atividades sociais (clubes de leitura e dramatização, autocontrole dos alunos etc.) e, sobretudo, ensinar a ler por prazer, como um hábito para toda a vida". (ALBERTO, 1932, s/p.).

A educadora apontava trabalhos que deveriam ocorrer dentro do espaço da biblioteca, como exposições de livros e gravuras organizadas pelos próprios frequentadores da biblioteca e pequenas palestras feitas a convite, que segundo Armanda deveriam ser ministradas por "pessoas capazes de interessar auditório tão exigente". (ALBERTO, 1932, s/p.) Outra atividade importante para Armanda era a hora do conto que para 
ela seria conduzido por uma bibliotecária; ela destacava que os trabalhos realizados na biblioteca remetiam as tarefas sociais como a colaboração, coparticipação e solidariedade, a partir do trabalho conjunto entre crianças, jovens, adultos e bibliotecários.

Aliás, a posição deste profissional na instituição é de suma importância para a educadora; ela mencionava que o sucesso da Biblioteca Pública de Nova York, em relação ao seu trabalho educativo, se devia ao "corpo de bibliotecários profissionais, formados em cursos universitários, equivalentes ao do magistério primário ou secundário com quem partilham as funções educacionais". (ALBERTO, 1934, s/p.).

A presença do bibliotecário, para ela não se restringia a educação juvenil. Armanda pensava que o profissional era relevante na educação de jovens e adultos, e neste sentido relatava:

Assim, o que importa não é dar ao adulto que começa a ler uma bela obra literária, mas sim um livro qualquer - seja ele o Rocambole! - que lhe agrade, que lhe desperte o gosto, estabelecese o hábito - e só dependerá do bibliotecário a direção futura desse hábito (ALBERTO, 1934, s/p.).

Deste modo, o bibliotecário possuía um papel importante na educação dos homens e mulheres de maior idade das classes proletárias, pois o profissional, a partir de leituras que agradassem os adultos poderia desenvolver junto a eles, o gosto e o hábito do ler. Entretanto, para tais atribuições, o bibliotecário deveria ser capacitado, de modo que a eficácia e eficiência destas instituições seriam de responsabilidade do mesmo,

A eficiência da biblioteca [...] depende muito mais do bibliotecário do que de um rico aparelhamento material. Assim, o cargo de bibliotecário deve ser exercido por profissionais aptos para a função de educadores do povo. (ALBERTO, 1934, s/p.).

A necessidade de bibliotecas para adultos surgia da primordialidade de uma educação extraescolar, estes espaços dedicados à escolarização de adultos que ficariam localizados em indústrias, comunas, e outros lugares para o uso de operários. Armanda citava países como U.R.S.S, a Tchecoslováquia e os Estados Europeus que construíram suas bibliotecas populares:

Na U. R. S. S. toda a organização de bibliotecas públicas é devida ao Estado. Tal é a importância atribuída à sua função, que não há fábrica, escola, quartel, estabelecimento agrícola, colônia correcional, sindicato - que não conte com a sua biblioteca. (ALBERTO, 1934, s/p.).

Na Tchecoslováquia, as comunas são obrigadas pela lei a manter cada uma a sua biblioteca, controlada pelo Ministério de Instrução Pública e pelo Instituto Masaryk, de educação de adultos. Em 
1930,essas bibliotecas de caráter regional eram cerca de 16.500, com 700.000 livros,20\% dos quais devem versar sobre assuntos de interesse especial da população local. Havia naquele ano - e não deixa de ser uma nota significativa - 50.000 bibliotecários servindo nas bibliotecas populares, dos quais, a maior parte, era de voluntários. (ALBERTO, 1934, s/p.).

Na Bélgica, na Suécia, na Finlândia e na Dinamarca as comunas também são obrigadas, explícita ou implicitamente a manter bibliotecas populares. (ALBERTO, 1934, s/p.).

Em relação ao Brasil, a educadora criticava a atuação das bibliotecas brasileiras que não apresentavam dispositivos para atrair o público operário. Em uma pesquisa realizada pela educadora, que objetivava determinar as leituras preferidas dos usuários da Biblioteca Nacional, ela descobriu que a predileção era por literatura, seguida por Ciências Médicas, filologia, linguísticas. Deste modo, concluiu que a instituição não era frequentada por leitores operários, mas estudantes universitários.

Armanda criticava a Biblioteca Nacional que no período se constituía como a principal instituição de leitura no Distrito Federal (RJ), desta forma, a educadora opinava que o horário de funcionamento do estabelecimento não se adequava aos tempos de lazer e descanso da classe trabalhadora, e com isso afirmava:

O regime de funcionamento da Biblioteca também não é democrático: fechada aos domingos e feriados (pois nesses dias só funciona a Seção de Periódicos), sem filiais ou simples depósitos de livros espalhados pelos subúrbios, sem serviços ambulantes para as zonas afastadas do Distrito Federal e estados próximos, sem serviços circulantes, sem o livre acesso às estantes com exigências de um cartão-passaporte válido para a frequência durante um ano, além de outras características negativas. (ALBERTO, 1934, s/p.).

Neste sentido no discurso da educadora, o operário não possuía incentivos para frequentar o espaço, pois como dizia Armanda "onde se viu biblioteca popular fechada nos dias de folga dos trabalhadores?" (ALBERTO, 1934, s/p.).

Armanda, também, criticava a falta de renovação e modernização do acervo das bibliotecas; segundo a educadora na Biblioteca Nacional "não se encontravam edições recentes, pelo menos das obras de maior repercussão dos centros cultos da Europa e América". (ALBERTO, 1934, $\mathrm{s} / \mathrm{p}$.) Entretanto salientava que a falta de aquisição de materiais novos se dava pela falta de investimentos nas bibliotecas e isso ocorria também na Biblioteca Municipal do Rio de Janeiro, onde a educadora relatava que "também é desprovida de serviços modernos para a circulação dos livros". (ALBERTO, 1934, s/p.). 


\section{Conclusão}

Cecília Meireles e Armanda Álvaro Alberto são importantes protagonistas da cena educacional dos anos 30, período marcado por tensões sociais, culturais e políticas que viam nos ideais inovadores e modernizadores, uma esperança para a sociedade que se transformava. As duas educadoras são reflexos do tecido social que modificava e criava novas tensões e viam a escola como lugar propício para a construção de uma nova sociedade.

Ambas compartilhavam o desejo de uma instituição escolar leiga, gratuita e de qualidade para todos, sejam crianças, adolescentes, jovens e adultos. Cecília Meireles e Armanda Álvaro Alberto lutaram pela aplicação das ideias da "escola nova" nos métodos e práticas pedagógicas em relação ao livro e a leitura, assim como nas bibliotecas públicas e escolares.

A questão das Bibliotecas Públicas e Escolares nos discursos foi marcante para as duas - Cecília Meireles atuou e arquitetou o que se considera como a primeira Biblioteca Pública Infantil do Brasil, o Pavilhão Mourisco - que mesmo com seu pequeno tempo de funcionamento conseguiu inúmeros adeptos e conseguiu materializar ideias que se tornaram práticas, que até na atualidade são consideradas inovadoras no campo da biblioteconomia.

Já Armanda acreditava no papel da biblioteca como potencializadora da prática educativa em crianças, jovens e adultos; a educadora percebia que a instituição poderia transformar a trajetória dos sujeitos que a frequentassem; para isso era necessária uma biblioteca com espaço adequado, acervo amplo, diversificado e de qualidade e tempo disponível para que todos pudessem utilizá-la.

Ao resgatar os discursos das duas educadoras, pode-se rever, recriar e remontar a história das bibliotecas, bibliotecários e leitores para entender as especificidades e singularidades do passado. Para a História das Bibliotecas e Bibliotecários Brasileiros, conhecer o legado de educadores, autores e intelectuais que pensaram e lutaram por mais bibliotecas é importante para a compreensão do trajeto sócio histórico da instituição bibliotecária. Além disso, neste resgate foi possível identificar a percepção de Armanda Álvaro Alberto e Cecília Meireles em relação ao bibliotecário. Para as educadoras, o profissional possui uma atuação fundamental na mediação da leitura para a construção do prazer de ler e um papel colaborativo no desenvolvimento social e educativo de crianças, jovens e adultos. Deste modo, perceber a importância que ambas davam a presença do bibliotecário alicerça ainda mais a identidade profissional.

Neste sentido, identificar as contribuições dos discursos e experiência de Cecília Meireles e Armanda Álvaro Alberto faz-se essencial para pensar como se coloca a biblioteconomia na atualidade. Pois, rever e estudar o ontem não significa colocá-lo como modelo a ser imitado no hoje, porém entender o passado em sua singularidade e especificidade 
possibilita alargar o diálogo com o presente e intensificar a compreensão das questões postas na atualidade.

\section{Referências}

ALBERTO, Armanda Álvaro. Biblioteca para crianças e adolescentes. TicoTico, Rio de Janeiro, p. 14, fev. 1930. s/p.

ALBERTO, Armanda Álvaro. Inquérito sobre Leituras Infantis. Jornal do Commercio, Rio de Janeiro, maio 1928. s/p.

ALBERTO, Armanda Álvaro. Leitura para adultos (o problema da biblioteca popular). Jornal do Comércio, 11 mar. 1934. Tese apresentada na VI Conferência Nacional de Educação. Fortaleza, 1934. s/p.

ALBERTO, Armanda Álvaro. Pela criação de bibliotecas públicas infantis. $O$ Estado, Niterói, 06 abr. 1932. s/p.

CUNHA, Marcus Vinicius da; SOUZA, Aline Vieira de. Cecília Meireles e o temário da escola nova. Cadernos de Pesquisa, São Paulo, v. 41, n. 144, set./dez. 2011. Disponível em: <http://www.scielo.br/scielo.php?pid=S0100-

15742011000300011 \&script=sci_arttext>. Acesso em: 08 jan. 2013.

EL FAR, Alessandra. Livros para todos os bolsos e gostos. In: ABREU, Márcia; SCHAPOCHNIK, Nelson. (Org.). Cultura letrada no Brasil: objetos e práticas. Campinas; São Paulo: Mercado de Letras, 2005. p. 329-34.

LOBO, Yolanda Lima. Cecília Meireles. Recife: Fundação Joaquim Nabuco: Editora Massangana, 2010.

MEIRELES, Cecília. Crônicas de educação 1. Rio de Janeiro: Nova Fronteira: Fundação Biblioteca Nacional, 2001. (Cecília Meireles obra em prosa).

MEIRELES, Cecília. Crônicas de educação 4. Rio de Janeiro: Nova Fronteira: Fundação Biblioteca Nacional, 2001. (Cecília Meireles: obra em prosa).

MELLO, Cristiane Silva; MACHADO, Maria Cristina Gomes. As contribuições de Cecília Meireles para a leitura e a literatura infantil. Anuário de Literatura, Florianópolis, v. 13, n. 2, p. 4-21, 2008. Disponível em: <http://periodicos.ufsc.br/index.php/literatura/article/view/7359>.

Acesso em: 15 dez. 2012.

MIGNOT, Ana Chrystina Venancio. Armanda Álvaro Alberto. Recife: Fundação Joaquim Nabuco : Editora Massangana, 2010.

MORAES, José Damiro de. Armanda Álvaro Alberto: pensamento e ação nos anos de 1930. In: CONGRESSO BRASILEIRO DE HISTORIA DA EDUCAÇÃO, 4, 2006, Goiânia. Trabalhos apresentados... [S.I]: Sociedade Brasileira de Historia da Educação, 2006. Disponível em: <http://www.sbhe.org.br/novo/congressos/cbhe4/individuais- 
coautorais/eixo06/Jose\%20Damiro\%20de\%20Moraes\%20-

\%20Texto.pdf> Acesso em: 12 dez. 2012.

SOARES, G. P. Leopoldo Lugones, Cecília Meireles e o cultivo das leituras literárias na infância. In: ABREU, Márcia; SCHAPOCHNIK, Nelson. (Org.). Cultura letrada no Brasil: objetos e práticas. Campinas; São Paulo: Mercado de Letras, 2005. p. 435-451.

VEIGA, Cynthia Greive. História da educação. São Paulo: Ática, 2007.

VIDAL, Diana Gonçalves. Práticas de leitura na escola brasileira dos anos 1920 e 1930. In: GALVÃO, Ana Maria de Oliveira; FARIA FILHO, Luciano Mendes de. Modos de ler, formas de escrever: estudos de história da leitura e da escrita no Brasil. Belo Horizonte: Autêntica, 1998. 